\title{
A Stochastic Programming Model to Solve the Capacity Expansion Problem Considering Auxiliary Tools: A Semiconductor Foundry Case
}

\author{
Yin-Yann Chen \\ Department of Industrial Management, National Formosa University, Taiwan
}

Copyright $(2016$ by authors, all rights reserved. Authors agree that this article remains permanently open access under the terms of the Creative Commons Attribution License 4.0 International License

\begin{abstract}
This study developed an extended stochastic programming model for the deterministic approach proposed by Chen, Chen and Liou [1]. Capacity planning, which plays a role in production planning, is a challenging problem for the semiconductor manufacturing industry. This study dealt with the uncertain demands of customers for a foundry industry in Taiwan. Through three scenarios, the stochastic programming model was exploited to solve the optimal medium-term capacity planning problem. The data collected from a real wafer foundry in Taiwan were treated as a fundamental scenario to demonstrate the value of the proposed stochastic programming model. The forecast demand variations in other scenarios complied with a normal distribution. The effect of the different probability distributions of demand scenarios on capacity allocation was considered. Changes in the customer order fulfillment rate or capacity utilization rate were analyzed from a series of capacity planning tests with varying demands of the initial customer. Based on different demand scenarios, the numerical results in this study revealed the concordance between the deterministic model and the proposed stochastic programming model. This stochastic programming model also expressed the flexible consideration of auxiliary tools and the increasing number of certified fabrication to the capacity planning problem in the wafer foundry.
\end{abstract}

Keywords Stochastic Programming, Capacity Allocation, Semiconductor Industry

\section{Introduction}

The semiconductor industry is a key industry for many countries, including Taiwan. It currently has the most significant effect on determining the cost and increasing the functioning of all electronic systems, information technology, telecommunications, and automation, among others. Products from the semiconductor industry are widely used in life, especially in the fields of electronics and communications (mobile device, computer, and tablet).

Chou, Cheng, Yang and Liang [2] indicated that the main problem in the three levels of capacity planning (long, medium, and short terms) is the capacity allocation among job orders and alternative routing planning. In fact, the capacity allocation in semiconductor manufacturing has become complicated because of the production requirement for a variety of products in different production facilities.

The objectives of this study are as follows:

1. This study purposes an extended stochastic model for the deterministic approach proposed by Chen, Chen and Liou [1]. The proposed stochastic programming model is constructed based on a multi-stage stochastic model with different scenarios through the change in customer demand.

2. The optimal capacity allocation for production under uncertain demand is determined. The problem focuses on effectively enhancing the capacity utilization of each manufacturing process in each factory within the planning horizon.

3. The validity and the flexibility of the stochastic programming model are demonstrated by comparing its results with those of the deterministic model. The effects of some input factors on the objective function of the stochastic model, the number of preferred fabrication, and the sale price of a product are analyzed.

A considerable number of studies have been conducted on capacity planning problems. Some studies have analyzed the effects of these problems on investment cost or profit. The topics of such research can be classified based on the capacity planning problem such as the following: (1) the tools to expand or the configuration for capacity planning management and (2) the capacity planning problem under uncertain demands of customers/ uncertain capacity/ price variation. The capacity planning problem is also studied under the combination of uncertain factors. The topics of the 
capacity planning problem can also be categorized based on different production environments: (1) single-site capacity planning problem, (2) multi-site capacity planning problem without new site installation, and (3) multi-site capacity planning problem with new site installation.

Many topics are studied for the single-site capacity planning problem in the semiconductor industry. The main issue in this problem is the decision on the amount of investment and the selection and efficient allocation of resources as addressed by Uribe, Cochran and Shunk [3]. A practical model is constructed to minimize the required investment in capacity planning for discrete manufacturing sites under an uncertain demand stream. Related to the capacity planning of simultaneous resources involving investments in alternative equipment, Wang and Hou [4] and Wang, Wang and Yang [5] conducted a preliminary study on a semiconductor testing facility. They argued that capacity planning and allocation are also extremely challenging in the wafer testing industry because of the constrained budget to invest, the limited capacity of resources, and the lumpy demands from semiconductor manufacturing fabs.

In consideration of the multi-site capacity planning problem without new site installation, Karabuk and $\mathrm{Wu}$ [6] classified the strategic capacity of the semiconductor industry into two main components, namely, capacity expansion and configuration. Y1lmaz and Catay [7] developed a formulation to solve the strategic planning problem for a three-stage production-distribution network. A production-distribution system contains a single item, multiple suppliers, and multiple producers. The multi-site capacity planning problem with new site installation is also called capacitated facility location and strategic supply chain network design. MirHassani, Lucas, Mitra, Messina and Poojari [8] classified the entire semiconductor manufacturing chain into three major stages, namely, production and packing in plants, distribution centers, and customer zones.

\section{Proposed Methodology}

Customer demand is one of the uncertain parameters in supply chain management. The proposed stochastic model is extended on the basis of the deterministic model proposed by Chen, Chen and Liou [1] to obtain a robust capacity planning decision under uncertain demand. By adding the scenario index for the stochastic model, we modify some parameters and other variables defined in the deterministic model by Chen, Chen and Liou [1] as follows:

\section{- Index}

i, customer index, $\mathrm{i}=1,2, \ldots \mathrm{I}$

$\mathrm{j}$, factory index, $\mathrm{i}=1,2, \ldots \mathrm{J}$

$\mathrm{t}$, period index, $\mathrm{i}=1,2, \ldots \mathrm{T}$

$\mathrm{k}$, product index, $\mathrm{i}=1,2, \ldots \mathrm{K}$

$\mathrm{s}$, scenario index $, \mathrm{s}=1,2,3$

\begin{tabular}{|c|c|}
\hline $\mathrm{de}_{\mathrm{ikt}}^{\mathrm{s}}$ & $\begin{array}{l}\text { Processing quantity required for product } \mathrm{k} \text { of customer } \mathrm{i} \text { in } \\
\text { period } \mathrm{t} \text { under scenario } \mathrm{s}\end{array}$ \\
\hline $\mathrm{p}^{\mathrm{s}}$ & Probability of scenario $s$ \\
\hline $\mathrm{W}_{\mathrm{ikf}}$ & Weighted value of factory $\mathrm{f}$ for product $\mathrm{k}$ of customer $\mathrm{i}$ \\
\hline $\mathrm{sp}_{\mathrm{ikt}}$ & Sale price for product $\mathrm{k}$ of customer $\mathrm{i}$ in period $\mathrm{t}$ \\
\hline $\mathrm{ca}_{\mathrm{kft}}$ & Capacity for product $\mathrm{k}$ at factory $\mathrm{f}$ in period $\mathrm{t}$ \\
\hline $\mathrm{cb}_{\mathrm{ikf}}$ & $\begin{array}{l}\text { If the product } \mathrm{k} \text { of customer } \mathrm{i} \text { can be processed at factory } \mathrm{f} \text {, } \\
\qquad \mathrm{cb}_{\mathrm{ikf}}=1 ; \text { otherwise, } \mathrm{cb}_{\mathrm{ikf}}=0\end{array}$ \\
\hline $\mathrm{mq}_{\mathrm{ik} 0}$ & Initial number of photo masks for product $\mathrm{k}$ of customer $\mathrm{i}$ \\
\hline $\mathrm{mu}_{\mathrm{ik}}$ & $\begin{array}{l}\text { Upper limit for the number of photo masks for product k of } \\
\text { customer i }\end{array}$ \\
\hline $\mathrm{lt}_{\mathrm{ik}}$ & $\begin{array}{l}\text { Lead time for purchasing the mask of product } \mathrm{k} \text { for } \\
\text { customer } \mathrm{i}\end{array}$ \\
\hline $\mathrm{mc}_{\mathrm{ikt}}$ & $\begin{array}{l}\text { Purchase cost of the mask for product } k \text { of customer } i \text { in } \\
\text { period } t\end{array}$ \\
\hline
\end{tabular}

- Decision Variables

The decision variables relate to the "here-and-now decision." The number of masks is decided to be purchased based on the order of customer and initial inventory products to keep up with the delivery time.

\begin{tabular}{|l|c|}
\hline $\mathrm{PM}_{\mathrm{ikt}}=$ & $\begin{array}{c}\text { Required purchasing number of masks for product } \mathrm{k} \text { of } \\
\text { customer } \mathrm{i} \text { in period } \mathrm{t}\end{array}$ \\
\hline $\mathrm{MQ}_{\mathrm{ikt}}=$ & Number of masks for product $\mathrm{k}$ of customer $\mathrm{i}$ in period $\mathrm{t}$ \\
\hline
\end{tabular}

In case of uncertain customer demand, the company needs to decide on the capacity allocation for each fabrication process under each scenario while obtaining the maximal profit and satisfying the customer requirement.

\begin{tabular}{|c|c|}
\hline $\mathrm{XQ}_{\mathrm{ikft}}^{\mathrm{s}}=$ & $\begin{array}{c}\text { Allocated capacity at factory } \mathrm{f} \text { for product } \mathrm{k} \text { of customer } \mathrm{i} \\
\text { in period } \mathrm{t} \text { under scenario } \mathrm{s}\end{array}$ \\
\hline $\mathrm{YQ}_{\mathrm{ikft}}^{\mathrm{s}}=$ & $\begin{array}{c}\text { Binary variable, } \mathrm{YQ}_{\mathrm{ikft}}^{\mathrm{s}}=1, \text { if customer } \mathrm{i} \text { acquires the } \\
\text { allocated capacity at factory f for product } \mathrm{k} \text { in period } \mathrm{t} \\
\text { under scenario } \mathrm{s} ; \mathrm{YQ}_{\mathrm{ikft}}^{\mathrm{s}}=0 \text {, otherwise }\end{array}$ \\
\hline
\end{tabular}

\section{- Objective Function}

The objective of the problem is to effectively enhance the capacity utilization of each manufacturing process in each factory within the planning horizon to determine the optimal capacity allocation for production under uncertain demand. The annual capacity utilization is determined on the basis of the weighted value of the factory for each customer product, the allocated capacity in that factory for customer product under uncertain demand, and the relative capacity of the factory for this customer product. In case of uncertain customer demand, the probability for each scenario is added. The formulation detail is described in Equation (1).

$$
\sum_{\mathrm{s}=1}^{\mathrm{S}} \mathrm{p}^{\mathrm{S}} \times \sum_{\mathrm{k}=1}^{\mathrm{K}} \sum_{\mathrm{f}=1}^{\mathrm{F}} \sum_{\mathrm{t}=1}^{\mathrm{T}}\left[\frac{\sum_{\mathrm{i}=1}^{\mathrm{T}}\left(\mathrm{w}_{\mathrm{ikf}} \times \mathrm{XQ}_{\mathrm{ikft}}^{\mathrm{S}}\right)}{\mathrm{ca}_{\mathrm{kft}}}\right]
$$

\section{- Constraints}

1. Constraints for the first stage (here-and-now decision)

The balance equations for the number of manufactured photo masks for each period time (month) are shown in Constraints (2) and (3).

$$
\begin{array}{r}
\mathrm{MQ}_{\mathrm{ik} 0}=\mathrm{mq}_{\mathrm{ik} 0} \quad \forall \mathrm{i}, \mathrm{k} \\
\mathrm{MQ}_{\mathrm{ikt}}=\mathrm{MQ}_{\mathrm{ik}(\mathrm{t}-1)}+\mathrm{PM}_{\mathrm{ikt}} \quad \forall \mathrm{i}, \mathrm{k}, \mathrm{t}
\end{array}
$$


Without the forecast demand, the simulated expanded capacity in each factory is calculated by purchasing a quantity of auxiliary tool (photo mask), that is, the total number of manufactured masks for each month is equal to the number of manufactured masks in the previous month plus the number of purchased masks in the current month.

During the production time, the factory actually does not have to buy extra masks. Thus, the number of purchased masks is equal to zero as addressed in Constraint (4). Constraint (5) is an upper limit in the amount of mask sets because of the diversity in semiconductor products and the uncertain life cycle of products.

$$
\begin{gathered}
\mathrm{PM}_{\mathrm{ikt}}=0 \forall \mathrm{i}, \mathrm{k}, \mathrm{t} \leq \mathrm{lt}_{\mathrm{ikt}} \\
\mathrm{MQ}_{\mathrm{ikt}} \leq \mathrm{mu}_{\mathrm{ik}} \forall \mathrm{i}, \mathrm{k}, \mathrm{t}
\end{gathered}
$$

Constraint (6) imposes non-negative conditions for the number of mask or purchasing mask in the first-stage decision.

$$
\mathrm{PM}_{\mathrm{ikt}}, \mathrm{MQ}_{\mathrm{ikt}} \geq 0 \forall \mathrm{i}, \mathrm{k}, \mathrm{f}, \mathrm{t}
$$

2. Constraints for the second stage (wait-and-see decision)

In the second stage, capacity allocation is determined in the case of different scenarios of forecast demand. Constraints (7) and (8) indicate that the allocation capacity for various products in each factory cannot exceed the customer requirements and satisfy the fixed capacity of the wafer foundry.

$$
\begin{gathered}
\sum_{\mathrm{f}=1}^{\mathrm{F}} \mathrm{XQ}_{\mathrm{ikft}}^{\mathrm{s}} \leq \mathrm{de}_{\mathrm{ikt}}^{\mathrm{s}} \quad \forall \mathrm{i}, \mathrm{k}, \mathrm{f}, \mathrm{t}, \mathrm{s} \\
\sum_{\mathrm{i}=1}^{\mathrm{I}} \mathrm{XQ}_{\mathrm{ikft}}^{\mathrm{s}} \leq \mathrm{ca}_{\mathrm{ikt}} \quad \forall \mathrm{i}, \mathrm{k}, \mathrm{f}, \mathrm{t}, \mathrm{s}
\end{gathered}
$$

Constraint (9) ensures that that the product produced in each factory can fulfill the production process (in which certificated fabrication has the production capability to satisfy the customer production requirement).

$$
\mathrm{YQ}_{\mathrm{ikft}}^{\mathrm{s}} \leq \mathrm{cb}_{\mathrm{ikf}} \quad \forall \mathrm{i}, \mathrm{k}, \mathrm{f}, \mathrm{t}, \mathrm{s}
$$

Constraint (10) is the basic condition for the allocated capacity variable in the integer stochastic model.

$$
\mathrm{XQ}_{\mathrm{ikft}}^{\mathrm{s}} \leq \mathrm{M} \times \mathrm{YQ}_{\mathrm{ikft}}^{\mathrm{s}} \quad \forall \mathrm{i}, \mathrm{k}, \mathrm{f}, \mathrm{t}, \mathrm{s}
$$

The existence of allocated capacity is addressed in Constraint (11), in which the total allocated capacity of all products in each factory cannot exceed the number of available masks.

$$
\sum_{f=1}^{\mathrm{F}} \mathrm{YQ}_{\mathrm{ikft}}^{\mathrm{S}} \leq \mathrm{MQ}_{\mathrm{ikt}} \quad \forall \mathrm{i}, \mathrm{k}, \mathrm{f}, \mathrm{t}, \mathrm{s}
$$

Constraint (12) is the cost limit to purchase mask. The total sale of products should be larger than the cost of purchasing new masks to reach the highest profit and expanded capacity.

$$
\sum_{\mathrm{t}=1}^{\mathrm{T}} \sum_{\mathrm{f}=1}^{\mathrm{F}}\left(\mathrm{sp}_{\mathrm{ikt}} \times \mathrm{XQ}_{\mathrm{ikft}}^{\mathrm{s}}\right) \stackrel{\sum_{\mathrm{t}=1}^{\mathrm{T}} \mathrm{mc}_{\mathrm{ikt}} \times \mathrm{PM}_{\mathrm{ikt}} \leq}{\forall \mathrm{i}, \mathrm{k}, \mathrm{t}, \mathrm{s} \quad(12)}
$$

Constraint (13) is the binary restriction for the allocation capacity decision. Constraint (14) refers to the basic restriction for the second-stage decision variable.

$$
\begin{gathered}
\mathrm{YQ}_{\mathrm{ikft}}^{\mathrm{s}} \in\{0,1\} \forall \mathrm{i}, \mathrm{k}, \mathrm{f}, \mathrm{t}, \mathrm{s} \\
\mathrm{XQ}_{\mathrm{ikft}}^{\mathrm{s}} \geq 0 \quad \forall \mathrm{i}, \mathrm{k}, \mathrm{f}, \mathrm{t}, \mathrm{s}
\end{gathered}
$$

\section{- Capacity Utilization Rate Calculation}

The capacity utilization rate of each fabrication for each month under each scenario demand variation is calculated in Constraint (15). This formulation is structured to explore the effectiveness of the proposed stochastic model in different scenarios.

$$
\frac{\sum_{\mathrm{i}=1}^{\mathrm{I}} \sum_{\mathrm{k}=1}^{\mathrm{K}} \mathrm{XQ}_{\mathrm{ikft}}^{\mathrm{S}}}{\sum_{\mathrm{k}=1}^{\mathrm{K}} \mathrm{ca}_{\mathrm{ikt}}}
$$

\section{- Order Fulfillment Rate Calculation}

Constraint (16) determines if the order fulfillment rate of each customer is satisfied under variation demand. The order fulfillment rate is calculated for each customer in each month in different demand scenarios.

$$
\frac{\sum_{\mathrm{k}=1}^{\mathrm{K}} \sum_{\mathrm{f}=1}^{\mathrm{F}} \mathrm{XQ}_{\mathrm{ikft}}^{\mathrm{S}}}{\sum_{\mathrm{k}=1}^{\mathrm{K}} \mathrm{de}_{\mathrm{ikt}}^{\mathrm{S}}}
$$

\section{Results}

The capacity utilization rate of each factory under different demand scenarios is detailed in Table 1. High values are generated in fabs 5 and 3 because of the high weight of production for the manufacturing process. A high variation in customer demand indicates a high variation in the utilization rate for each fabrication. This finding is clearly shown in the third and fourth seasons, especially in the fourth season of the year. The capacity utilization rate of each factory reaches the lowest value under a low customer demand. These values increase with customer demand. 
Table 1. The capacity utilization rate of each factory under different demand scenarios

\begin{tabular}{|c|c|c|c|c|c|c|c|c|c|c|c|c|c|}
\hline \multirow{2}{*}{$\mathrm{Fab}$} & \multirow{2}{*}{$\begin{array}{l}\text { Demand } \\
\text { variation }\end{array}$} & \multicolumn{12}{|c|}{ Time (month) } \\
\hline & & Jan. & Feb. & Mar. & Apr. & May & Jun. & Jul. & Aug. & Sep. & Oct. & Nov. & Dec. \\
\hline \multirow[t]{3}{*}{ Fab1 } & Low & $51 \%$ & $56 \%$ & $55 \%$ & $53 \%$ & $50 \%$ & $50 \%$ & $48 \%$ & $46 \%$ & $38 \%$ & $29 \%$ & $23 \%$ & $15 \%$ \\
\hline & Average & $62 \%$ & $63 \%$ & $65 \%$ & $66 \%$ & $68 \%$ & $69 \%$ & $68 \%$ & $67 \%$ & $62 \%$ & $62 \%$ & $62 \%$ & $62 \%$ \\
\hline & High & $66 \%$ & $69 \%$ & $72 \%$ & $76 \%$ & $87 \%$ & $94 \%$ & $96 \%$ & $92 \%$ & $80 \%$ & $80 \%$ & $82 \%$ & $84 \%$ \\
\hline \multirow[t]{3}{*}{ Fab2 } & Low & $55 \%$ & $47 \%$ & $41 \%$ & $39 \%$ & $35 \%$ & $31 \%$ & $23 \%$ & $14 \%$ & $9 \%$ & $13 \%$ & $11 \%$ & $7 \%$ \\
\hline & Average & $53 \%$ & $65 \%$ & $64 \%$ & $67 \%$ & $76 \%$ & $82 \%$ & $81 \%$ & $76 \%$ & $70 \%$ & $59 \%$ & $54 \%$ & $54 \%$ \\
\hline & High & $57 \%$ & $74 \%$ & $75 \%$ & $83 \%$ & $98 \%$ & $99 \%$ & $100 \%$ & $100 \%$ & $100 \%$ & $94 \%$ & $95 \%$ & $97 \%$ \\
\hline \multirow[t]{3}{*}{ Fab3 } & Low & $70 \%$ & $71 \%$ & $68 \%$ & $69 \%$ & $67 \%$ & $71 \%$ & $57 \%$ & $49 \%$ & $39 \%$ & $21 \%$ & $17 \%$ & $11 \%$ \\
\hline & Average & $73 \%$ & $82 \%$ & $92 \%$ & $98 \%$ & $98 \%$ & $98 \%$ & $96 \%$ & $96 \%$ & $96 \%$ & $96 \%$ & $96 \%$ & $96 \%$ \\
\hline & High & $69 \%$ & $98 \%$ & $98 \%$ & $99 \%$ & $99 \%$ & $99 \%$ & $98 \%$ & $98 \%$ & $98 \%$ & $98 \%$ & $98 \%$ & $98 \%$ \\
\hline \multirow[t]{3}{*}{ Fab4 } & Low & $50 \%$ & $55 \%$ & $55 \%$ & $55 \%$ & $55 \%$ & $55 \%$ & $55 \%$ & $54 \%$ & $43 \%$ & $34 \%$ & $28 \%$ & $18 \%$ \\
\hline & Average & $50 \%$ & $58 \%$ & $55 \%$ & $74 \%$ & $80 \%$ & $91 \%$ & $91 \%$ & $85 \%$ & $85 \%$ & $71 \%$ & $65 \%$ & $56 \%$ \\
\hline & High & $66 \%$ & $74 \%$ & $73 \%$ & $100 \%$ & $100 \%$ & $100 \%$ & $100 \%$ & $100 \%$ & $100 \%$ & $100 \%$ & $100 \%$ & $98 \%$ \\
\hline \multirow[t]{3}{*}{ Fab5 } & Low & $88 \%$ & $88 \%$ & $93 \%$ & $96 \%$ & $90 \%$ & $82 \%$ & $66 \%$ & $51 \%$ & $41 \%$ & $31 \%$ & $24 \%$ & $14 \%$ \\
\hline & Average & $91 \%$ & $100 \%$ & $100 \%$ & $100 \%$ & $100 \%$ & $100 \%$ & $100 \%$ & $100 \%$ & $100 \%$ & $99 \%$ & $99 \%$ & $99 \%$ \\
\hline & High & $91 \%$ & $100 \%$ & $100 \%$ & $100 \%$ & $100 \%$ & $100 \%$ & $100 \%$ & $100 \%$ & $100 \%$ & $100 \%$ & $100 \%$ & $100 \%$ \\
\hline
\end{tabular}

Considering the large number of order in some months for special products, the company needs to purchase masks to satisfy the customer requirement. The result of the number of purchasing masks for each manufacturing site is depicted in Figure 1.

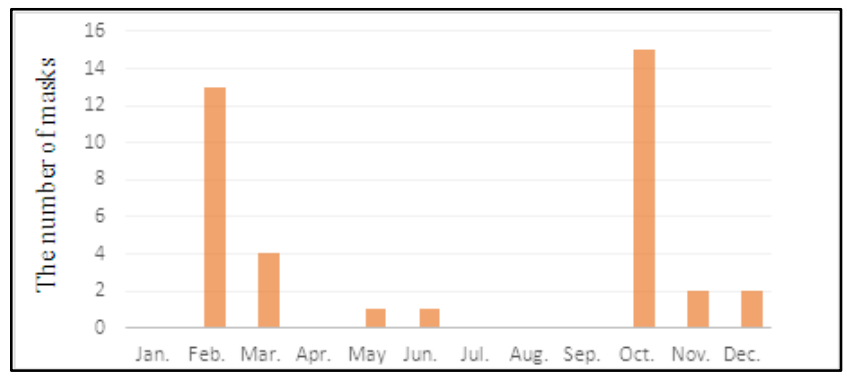

Figure 1. The number of purchasing masks

The result indicates that the current production is deficient for the customer demand in February, March, May, and the last three months of the year. This finding also signifies the large number of purchasing masks in the busy season of the year (February and October). High exigent production is highlighted when customer demand becomes high before important holidays, such as the Lunar New Year (February) and Christmas Day (December), during which the promotion of retail or wholesale occurs.

This study calculates the expected value of perfect information (EVPI) and the value of stochastic solution (VSS) to demonstrate the flexibility and validity of the stochastic model. The results of EVPI and VSS are non-negative, thus implying the concordant solution of the stochastic model although the EVPI is small. The results about these related indicators are shown in Table 2.
Table 2. The results about related indicators

\begin{tabular}{ccccc}
\hline $\begin{array}{c}\text { Objective value of } \\
\text { stochastic } \\
\text { programming } \\
\text { model (SP) }\end{array}$ & $\begin{array}{c}\text { Objective } \\
\text { value of wait } \\
\text { and see model } \\
\text { (WS) }\end{array}$ & $\begin{array}{c}\text { Expected } \\
\text { value } \\
\text { Solution } \\
\text { (EEV) }\end{array}$ & $\begin{array}{c}\text { Expected value } \\
\text { of perfect } \\
\text { information } \\
\text { (EVPI) }\end{array}$ & $\begin{array}{c}\text { Value of } \\
\text { stochastic } \\
\text { solution } \\
\text { (VSS) }\end{array}$ \\
\hline 83.102 & 83.103 & 83.060 & 0.001 & 0.042 \\
\hline
\end{tabular}

\section{Conclusions}

The usefulness of the stochastic model in the capacity planning problem leads us to improve the deterministic model developed by Chen, Chen and Liou [1]. Capacity utilization is examined in consideration of the importance level of the preferred production sites. The proposed stochastic model is implemented in the wafer foundry in Taiwan. The production begins after the orders are received. In case of varied customer demands, the proposed stochastic model is constructed with known probability coefficients. This model helps decision makers decide on the capacity allocation among multiple fabs in terms of a mid-term goal to meet the customer requirement as a short-term goal.

By comparing the proposed stochastic model with the deterministic model, we obtain the following similar results: (1). The increasing flexibility of production is identified using auxiliary tools (purchasing masks). The capacity and customer demand utilization rates are enhanced. (2). Accompanied with purchasing masks, the increasing number of certified fabs can increase the capacity flexibility although it is not implementable in practice because the production practically requires some months (or even a year) to verify products.

EVPI and VSS are calculated to demonstrate the flexibility of the proposed stochastic model. The positive 
results show the suitability of the proposed model. The small values of EVPI and VSS pose a problem in the database of demand variation. The variation in product price insignificantly affects the capacity utilization in contrast to the increasing number of certified fabs.

\section{REFERENCES}

[1] Y.-Y. Chen, T.-L. Chen, C.-D. Liou, Medium-term multi-plant capacity planning problems considering auxiliary tools for the semiconductor foundry, Int J Adv Manuf Technol, 64 (2013) $1213-1230$.

[2] Y.-C. Chou, C.T. Cheng, F.-C. Yang, Y.-Y. Liang, Evaluating alternative capacity strategies in semiconductor manufacturing under uncertain demand and price scenarios, International Journal of Production Economics, 105 (2007) 591-606.

[3] A.M. Uribe, J.K. Cochran, D.L. Shunk, Two-stage simulation optimization for agile manufacturing capacity planning, International Journal of Production Research, 41 (2003) 1181-1197.

[4] K.J. Wang, T.C. Hou, Modelling and resolving the joint problem of capacity expansion and allocation with multiple resources and a limited budget in the semiconductor testing industry, International Journal of Production Research, 41 (2003) 3217-3235.

[5] K.J. Wang, S.M. Wang, S.J. Yang, A resource portfolio model for equipment investment and allocation of semiconductor testing industry, European Journal of Operational Research, 179 (2007) 390-403.

[6] S. Karabuk, S.D. Wu, Coordinating Strategic Capacity Planning in the Semiconductor Industry, Operations Research, 51 (2003) 839-849.

[7] P. Yilmaz, B. Catay, Strategic level three-stage production distribution planning with capacity expansion, Computers \& Industrial Engineering, 51 (2006) 609-620.

[8] S.A. MirHassani, C. Lucas, G. Mitra, E. Messina, C.A. Poojari, Computational solution of capacity planning models under uncertainty, Parallel Computing, 26 (2000) 511-538. 